\title{
A Modified Microteaching Model: A Cross-Disciplinary Approach to Faculty Development
}

\author{
John P. Hertel \\ Barbara J. Millis \\ Robert K. Noyd \\ United States Air Force Academy
}

Three departments at the United States Air Force Academy successfully used a microteaching model to train new faculty. Like other models, its structured approach used videotaping and peer coaching. The model also contained several unique features, including a cross-disciplinary approach to supplement feedback from department members and focused small group feedback with built-in preparation time. Thus, this model results not only in enhanced teaching performance, but also in departmental and institutional collegiality.

\section{INTRODUCTION}

66 A $t$ first I was fearful," confessed a new instructor in the management Adepartment at the United States Air Force Academy (USAFA). "Now I am convinced that microteaching truly influenced my classroom performance in a positive way." Three departments at USAFA-biology, law, and management-have integrated a microteaching component into their summer departmental orientations for new faculty members. The model used is a considerable modification of the original process, which has remained viable, particularly in graduate teaching assistant (GTA) training, since the 1960s. Involving both department faculty members 
and outside observers, the USAFA microteaching sessions result in rich feedback. Because of the opportunity not only for one-on-one feedback with a skilled facilitator, but also for carefully prepared feedback from small faculty groups, this model fosters collegiality and encourages the reflective insights needed for effective peer coaching and teaching enhancement.

\section{What Is Microteaching?}

Microteaching is defined by McKnight as "a scaled down realistic classroom training context in which teachers, both experienced and inexperienced, may acquire new teaching skills and refine old ones" (1980, p. 214). It was developed in the early and mid-1960s by Dwight W. Allen, Kevin Ryan (1969), and other colleagues at the Stanford Teacher Education Program. The Stanford model emphasized a teach, review and reflect, re-teach approach, using elementary school students as authentic audiences. It also focused on narrowly described skill sets. Videotaping a brief five- to ten-minute mini-lesson was a key component with considerable time devoted to the entire process.

Some subsequent modifications have eliminated the videotaping component altogether while maintaining an emphasis on a concentrated, focused form of feedback using role-playing peers, rather than actual students. Using faculty peers rather than actual students and allowing teachers to present skills of their own choosing during the mini-lesson results in a modification of microteaching which Tiberius (1997) calls laboratory teaching.

In the early models, often the peer audience and the instructor reviewed the videotape together after the mini-lesson, a tactic that was both time-consuming and repetitious. A more effective variation on this latter model, developed by Keesing and Daston (1979), eliminated the repetition by having the mini-lesson presenter and the facilitator review the tape privately while the peer audience prepared feedback emphasizing two skills specifically identified by the presenter.

Although many variations of microteaching exist, some basic premises behind the process remain constant.

- Microteaching is real teaching

- It lessens the complexities of normal classroom teaching in that class size, scope, and content are reduced

- It focuses on accomplishing specific tasks 
- It organizes controlled, structured practice sessions

- It allows for immediate, focused feedback

- It promotes reflection on teaching approaches and on constructive feedback

\section{THE USAFA MODEL}

The USAFA microteaching model, based on the Keesing and Daston approach, grew from a fruitful collaboration between the director of faculty development in USAFA's Center for Educational Excellence (CEE), who was trained by Hugo Keesing in 1984, and two proactive faculty members responsible for faculty development in their respective departments of law and biology. In the summer of 1999 , both departments involved their new faculty in microteaching activities and found the experience so positive that they repeated it with new faculty in 2000. Additionally, in 2000, the CEE faculty development expert and the law and biology specialists-now experienced microteaching facilitators-worked together to help the management department conduct microteaching sessions for an unusually high influx of new instructors, 14 in all.

The USAFA model contains several key steps.

\section{Prior to the Microteaching Session}

- Instructors plan a ten- to 15 -minute mini-lesson, preferably on a topic that they will later use for a full 50-minute lesson. In the biology and management departments, the instructor selected the topic; the law department facilitator deliberately assigned a topic from an early lesson to help faculty prepare for early classes.

- Instructors, after reflection, complete a mini-lesson form (Appendices 18.2 and 18.3) indicating, among other things, the lesson title and objectives and teaching skills/abilities on which they wish specific feedback.

\section{During the Microteaching Session}

- After distributing their mini-lesson forms to the faculty participants, instructors teach the ten- to 15-minute mini-lesson before colleagues as it is videotaped. Time is called, as needed. The faculty observers, most from the department but some outside the discipline, serve as the pseudo students. 
- The instructor and the microteaching facilitator spend the next ten minutes discussing the mini-lesson while they review the videotape. Special attention is paid to elements, such as mannerisms or movements, best captured by a camera.

- During this same ten minutes, colleagues in small groups discuss and plan a structured feedback session, emphasizing reinforcement of what went right and discussing how to lead the instructor toward positive changes. The roles of discussion leader, recorder, and spokesperson rotate within the small group.

- During the third ten-minute segment, the spokesperson for each group, representing the group's consensus, shares structured feedback with the instructor, concentrating on the specific feedback requested.

Typically, each small group offers, in turn, a positive commentsomething the instructor should continue doing-and then each group, in turn, focuses on something the instructor might improve.

- A give-and-take discussion among all participants ensues, if time and inclinations permit.

- Participants make individual comments on their copy of the presenter's mini-lesson form, which are then returned to the new instructor.

\section{The Context for Microteaching at USAFA}

All three USAFA departments were motivated to try a microteaching approach by an extrinsic factor: the dean of the faculty's requirement that all new faculty participate in practice teaching consisting of at least two classroom presentations with experienced faculty members observing in the role of students and providing constructive feedback. More importantly, though, all departments at USAFA are intrinsically motivated by a strongly perceived responsibility for training new instructors in methods specific to the discipline. All departments recognize the need to bring new faculty members-many of them young captains in the Air Force with master's degrees, but no teaching experience-up to speed in a relatively short period of time. With an average tour of approximately three years, USAFA military faculty members don't have the time to learn from their mistakes. Plus, teaching standards are exceptionally high: Like all USAFA faculty, newcomers are operating under institutional core values that emphasize "Excellence in All We Do." Thus, fac- 
ulty development is a responsibility jointly shared by the CEE and by the individual departments. In addition to a weeklong orientation program organized by CEE for over 140 new and returning faculty, all departments offer a discipline-specific orientation.

The biology department, for example, offered six hours of teacher training that included classroom management, principles of learning and pedagogy, and professional development.

The law department provided sequenced orientation sessions. The first of these involved an informal one-on-one meeting between the department's faculty development specialist (who also served as the microteaching facilitator) and the new faculty member. During a subsequent welcome by the department head, which included all the department members, the microteaching facilitator explained the microteaching procedures in greater detail, distributed the ten-minute minilesson plan form (Appendix 18.3) and the microteaching guidelines (Appendix 18.4). During a third meeting, the individual responsible for the core law course taught by all new instructors discussed how the microteaching topics assigned to new faculty fit into a full lesson and into the course. This orientation helped new faculty members appreciate the relevance of the microteaching lesson and also determined the level of detail they should present during the microteaching session. The microteaching sessions prior to the start of classes were followed by 50 minute presentations with focused feedback. After the semester began, all new faculty also received structured classroom observations.

The management department, working with the CEE, scheduled over a week of half-day orientation events for new faculty. Sessions included "Lesson Planning and the First Day of Class," "Active Learning: Quick Ways to Engage Cadets," "Testing and Grading: The Agony and the Ecstasy," "Using the Web Effectively," and culminated with two mornings of microteaching.

This context is essential. The microteaching sessions become more meaningful when placed within the broader context of an orientation to effective teaching at the Air Force Academy. Furthermore, by establishing a collegial context for sharing teaching ideas, new instructors are more likely to seek help with teaching later in the term. There is a tendency, as Kinsella notes, to avoid such consultations: "Novice and veteran professors alike may feel that to actively seek advice on curriculum, instruction or classroom management is admitting a lack of competence and a potential threat to their professional reputation and status within the department" (1995, p. 110). The emphasis on formative evaluation- 
feedback intended to strengthen teaching, not to evaluate faculty for administrative decisions-during this microteaching process allows faculty to experiment in a relatively risk-free environment.

\section{Factors Contributing to the Success OF THE Microteaching EXPERIENCE}

In addition to the positive context, several features of the USAFA microteaching model contributed to its success in all three departments. These features could be replicated in virtually any other academic setting.

\section{Structured Guidelines}

Faculty new to a department need to develop confidence in the department's policies and procedures, as well as in the people who will become working colleagues. Having a well-structured orientation program that addresses as many professional and personal issues as possible will promote a sense of belonging to a competent, caring institution. The law department's orientation, for example, included detailed discussions about the microteaching presentations, including their purpose and procedures. Discussing the actual forms used in the microteaching process overcame much of the new instructor's initial anxiety (see Appendices $18.1,18.2,18.3$, and 18.4).

\section{Departmental Involvement}

Having as many department members as possible participate in the microteaching sessions adds a dimension of collegiality and caring. Teachers with different levels of experience made for rich discussions within the small groups. During the mini-lesson, participants acted as typical students by asking and answering clarifying questions and, in a few cases, exhibiting real types of student behavior. The new faculty demonstrated a wonderful variety of teaching techniques-an added benefit to all participants, new and experienced. The value of reflection on teaching cannot be emphasized enough. As Killen notes, "There is a limit to how much you can learn from self-analysis. The benefits of reflection can be greatly enhanced if the process involves a sharing of ideas with a colleague" (1995, p. 129). Involving an entire department-or at least a large segment of it-results in rich, productive conversations about teaching and learning and engenders trust and collegiality. 


\section{Small Group Feedback Opportunities}

Most importantly, having the small groups of participant-observers prepare the feedback was tremendously valuable. The comments from each group typically reinforced important points and allowed for in-depth commentary. Multiple groups also offered different perspectives and permitted additional issues to emerge. On more than one occasion, one of the groups reacted one way to an instructor's technique while another group reacted exactly the opposite. Rather than providing confusing feedback, these occasions highlighted the fact that the technique employed was likely to produce similarly mixed reactions in students-a valuable lesson learned. Because the groups were deliberately small-four to five faculty members-there was ample opportunity for all voices to contribute. The discussions about teaching were rich and intimate, reinforcing Kinsella's emphasis on "a context that is supportive, non-evaluative, and intellectually stimulating.... This willingness and ability to take risks to teach more effectively, and to constantly monitor and adjust goals and strategies, can only be fostered within a trusting, collaborative environment" (1995, p. 109).

\section{Cross-Disciplinary Involvement}

Similarly, it was helpful to include participants who were not from the presenter's department and who did not have special knowledge of the topic presented. More than once, either during the mini-lesson itself or during the group discussions, these participants raised issues that the others did not see, perhaps because the subject matter experts had unconsciously filled in the blanks in the instructor's presentation. During the law department's microteaching sessions, two visiting nonlaw professors from a large state university and a nonteaching spouse of a faculty member added insightful comments and differing perspectives. While these last participants were unplanned (as visitors, they had expressed an interest in the microteaching procedures), they proved especially helpful. The three outside facilitators from biology, law, and English critiqued the management department's microteaching sessions.

In addition to these external insights, input from members of the department who are familiar with the lessons being taught is critical. These content expert participants are best able to determine whether the instructor is presenting the material at an appropriate level and in a way consistent with the department objectives. 


\section{Length of the Mini-Lesson}

Faculty new to a department, an institution, and a community have a myriad of demands on their time. Thus, new faculty appreciated the fact that they could teach an abbreviated lesson. Some found that a tenminute session was not intimidating, and a new faculty member also mentioned that the ten-to 15 -minute session allowed him to "work through a lesson plan, albeit abbreviated, which helped me establish a format for such plans that I'm still using."

\section{Videotaping}

Although some microteaching models omit the videotape portion, viewing the tape one-on-one with a facilitator had several important benefits. One was to provide feedback to the presenter on presentation mechanics such as voice, body position and movements, hand gestures, and eye contact, as well as recognizing student responses to the lesson. A second benefit was to allow the presenters to review, more as outsiders, how they presented the lesson. This previewing feature became beneficial during the group feedback sessions, since the instructors had observed their teaching before receiving feedback from the group, rather than being limited to memory. Davis also recognizes the value of videotaping: "Watching a videotape of yourself is an extremely valuable experience. Videotaping allows you to view and listen to the class as your students do..." (1993, p. 355).

Another important function of the video review was to provide the participants time to synthesize and prioritize their observations and construct meaningful feedback. Immediate feedback from individual observers often prompts idiosyncratic comments or even criticisms without reasoned recommendations for improvement. Also, during immediate feedback sessions a single comment often carries too much significance, particularly if it is negative. When small group discussions filtered and focused these individual criticisms, group consensus allowed for a more balanced perspective during the feedback to the presenter. Without fail, the group comments became more constructive.

\section{Feedback from New Faculty}

Approximately two months into the fall semester, all 18 of the new instructors from the management and law departments received the opportunity to provide feedback on this microteaching model. Nine of them responded, either with written email replies to questions asking for 
comments or in small group sessions with the authors. These comments, which were collected and examined, reinforced several key points.

The new instructors emphasized, first of all, that preparation for the microteaching process was essential. The mini-lesson forms were only useful where there was a discussion beforehand on how they would be used. Several faculty members indicated that more preparation would have been helpful. Secondly, the management instructors were allowed to select whatever topic they wanted from the courses they were to teach. While this choice put them into a comfort zone, several recommended that assigned topics would let them experiment with presentations, which they then could perfect before teaching their first real class. One commented, "The [assigned] lesson should be a new topic to show any weakness."

All of the presentations were videotaped, and the faculty presenters overwhelmingly considered the videotaping experiences very effective. One instructor commented, "You never know how your teaching comes off. This gives you a chance to be a fly on the wall and to be critical of yourself." More than one instructor agreed that seeing the videotape caused them to be less defensive during the group feedback sessions and allowed them to better understand and even agree with many of the comments, especially the negative ones.

All of the instructors agreed that it was essential for the participant groups to have time to compose their feedback, outside the presence of the presenter. And they agreed that the preparation/consensus-building time changed how the feedback was presented. One new faculty member wanted more "hardball" feedback. He felt that the comments from his colleagues were too kind: "Just tell me where I went wrong; where I blew it," he said. At the same time, he appreciated the value of constructive feedback, including the recommended improvements-"as long as [they] identify the shortcomings."

When asked what-besides more instruction on the microteaching process-they recommended most, there was clear consensus that new faculty members wanted more follow-up. Fortunately, this follow-up occurred because in all three departments routine classroom observations for new faculty are the norm. All agreed that the microteaching experience prepared them well for these multiple follow-up visits and encouraged them to pursue further conversations about teaching and learning.

"This is like a lab," one instructor commented. "It's where you're supposed to make mistakes in order to learn." Another remarked, "I got some good feedback... some things to put in my toolbox to use later." 


\section{Conclusion}

Because of its flexibility and efficiency, virtually any department can adapt this microteaching model. It is effective not only because it focuses attention on good teaching practices, but also because it promotes collegiality. This model requires minimal preparation for both the facilitator and the new faculty member. It allows neophyte teachers both rehearsal and feedback before entering an actual classroom. Once in the classroom, because they are accustomed to collegial peer review, they feel comfortable welcoming subsequent observations. This combination of microteaching and formative classroom observations-established practice at the Air Force Academy through the CEE and departmental initiatives-is a viable model for virtually any institution.

\section{REFERENCES}

Allen, D. W., \& Ryan, K. (1969). Microteaching. Reading, MA: Addison-Wesley.

Davis, B. G. (1993). Tools for teaching. San Francisco, CA: Jossey-Bass.

Keesing, H. A., \& Daston, M. (1979). How to run a microteaching workshop. College Park, MD: University of Maryland University College Faculty Development Program.

Killen, R. (1995). Improving teaching through reflective partnerships. In E. Neal (Ed.), To improve the academy: Vol. 14. Resources for faculty, instructional, and organizational development (pp. 125-141). Stillwater, OK: New Forums Press.

Kinsella, K. (1995). Peers coaching teaching: Colleagues supporting professional growth across the disciplines. In E. Neal (Ed.), To improve the academy: Vol. 14. Resources for faculty, instructional, and organizational development (pp. 107123). Stillwater, OK: New Forums Press.

McKnight, P. C. (1980). Microteaching: Development from 1968-1978. British Journal of Teacher Education, 6, 214-227.

Sahu, A. R. (1985). An introduction of microteaching: A systems approach. International Journal of Math, Education, Science, and Technology, 16, 25-31.

Tiberius, R. (1997). Microteaching, teaching laboratory, and alliances for change. In K. T. Brinko \& R. J. Menges (Eds.), Practically speaking: A sourcebook for instructional consultants in higher education. (pp. 131-137). Stillwater, OK: New Forums Press. 
Contact:

John P. Hertel

Assistant Professor of Law

HQ USAFA/DFL

2354 Fairchild Drive, Suite 1J-116

USAF Academy, CO 80840-6248

(719) 333-2950

(719) 333-9165 (Fax)

Email:John.hertel@usafa.af.mil

Barbara J. Millis

Director of Faculty Development

HQ USAF/DFE

2354 Fairchild Drive, Suite 4K25

USAFA Academy, CO 80840-6220

(719) 333-2549

Email: Barbara.millis@usafa.af.mil

Robert K. Noyd

Associate Professor of Biology

HQUSAFA/DFL

2354 Fairchild Drive

USAF Academy, CO 80840

(719) 333-2720

Email: Bob.Noyd@usafa.af.mil

John P. Hertel is Assistant Professor of Law at the United States Air Force Academy. For the past two years, he has directed the law department's New Faculty Orientation Program and has worked with the academy's Center for Educational Excellence to assist new faculty from other departments to prepare to teach.

Barbara J. Millis is Director of Faculty Development at the United States Air Force Academy, frequently offers workshops at professional conferences (American Association for Higher Education (AAHE), Lilly Teaching Conference, Council of Independent Colleges, etc.) and for various colleges and universities. She publishes articles on a range of faculty development topics and co-authored with Philip Cottell, Cooperative Learning for Higher Education Faculty, Oryx Press (now Greenwood). Her interests include cooperative learning, peer review, critical thinking, and writing for learning. After the Association of American Colleges and Universities (AAC\&U) selected the United States Air Force Academy as a Leadership Institution in Undergraduate Education, she began serving as the liaison to the AAC\&U's Great Expectations Consortium on Quality Education. 
Robert K. Noyd is Associate Professor of Biology at the United States Air Force Academy. He teaches a variety of biology courses, conducts scientific research, directs the department's curriculum development activities, and presents teaching workshops for academy faculty. 


\section{APPENDIX 18.1 \\ The Mini-Lesson: A Component Skills Approach}

Department of Biology, USAFA

Each new instructor will present a mini-lesson of 15 minutes to the faculty for assistance in improving their teaching skills.

\section{Mini-Lesson Components}

1) Lesson plan (see below) to provide context for the mini-lesson

2) Required teaching skills to present:

- Warm up or preparing student for lesson/activity

- Concept development

- Present a single concept

- Illustrating

- Closure or transition (if appropriate)

3) Include one of the following in your presentation

- Stimulus variation

- Questioning

- Silence and nonverbal cues

- Verbal reinforcement

- Recognizing student behaviors

\section{Topic}

Any topic from a general biology course. Select one that you can open and transition/close within a 15-minute time frame. Please complete the mini-lesson plan attached.

\section{DFB Faculty Role}

To give feedback and play the role of cadets by answering questions. Unless you are asked, please do not exhibit contrived student behaviors. 


\section{Feedback Session}

The mini-lesson will be videotaped. For 10 minutes following the minilesson:

- I will play back and go over the videotape with the instructor.

- DFB faculty will break up into small groups and give feedback on the required and selected teaching skills presented. Each group will give the instructor the three most important things they did effectively or can do to improve.

For the next 15 minutes, the instructor will receive feedback. 


\section{Appendix 18.2 \\ Mini-lesson Plan \\ Department of Biology, USAFA}

New instructors, please complete this form and make 15 copies

Instructor:

Course:

Lesson No:

Title:

Time frame within content block: beginning middle end

Previous lesson title:

What have students been asked to do in preparation?

\section{Teaching Methods}

Lesson Objectives/Goals: to Achieve Goal

Specific learning obstacles anticipated?

(lack of student interest, background, time in semester, etc.)

Feedback: An area in which I particularly want feedback is...

Colleague comments:

Warm Up: ___ Concept Development:

Other areas: 


\section{APPENDIX 18.3 \\ Ten-Minute Mini-Lesson Plan \\ Department of Law, USAFA}

Instructors, please bring ten copies of this form with the first four items completed.

Instructor:

Lesson title:

Lesson objectives:

Two ability areas on which I particularly want feedback:

Colleague comments: 


\section{APPENDIX 18.4 Microteaching Guidelines}

Prepared by B. Millis and distributed to law department faculty participating in microteaching sessions

A supportive, positive atmosphere characterizes microteaching sessions with an emphasis on supportive feedback and mutual reflection and discussion. The various participants assume different roles.

The INSTRUCTOR PRESENTING THE MINI-LESSON is in an active teaching role.

Prior to the microteaching session, you will prepare your ten-minute mini-lesson and complete the information form on which colleagues will write comments. You have several decisions to make, including your topic, your lesson objectives, and the teaching abilities on which you want specific feedback. If you choose a tried and true topic and request feedback on skills you already suspect are effective, then you will obviously perform well in front of your colleagues, a worthy goal to build confidence. On the other hand, such a polished presentation may not help your future teaching. A workshop such as this should involve risktaking, with deliberate exposures resulting in professional growth. Try to prepare a mini-lesson that will most benefit you and your future students. Select a topic that you expect to re-teach as a full 50-minute session. Remember also to select a topic and an approach that will interest your workshop colleagues.

During the session, before beginning your mini-lesson, rearrange the furniture (if possible) to provide a congenial classroom atmosphere. Keep your objectives in mind, also, so that if student participation is a concern, for example, the arrangement of the desks will not only encourage student-teacher or student-student interaction, but will also allow the cameraperson to capture the exchanges. Put material on the board or overhead or pass out handouts prior to or during the mini-lesson, just as you would do during a regular class session.

Immediately prior to the taping of your mini-lesson, you will review with the other workshop participants the information you have recorded on the form. During this review, keep two critical points in mind: 1) You must clearly identify the two skills/abilities you want feedback on so that your colleagues can concentrate selectively during your presentation, and 2) be certain not to confuse your pre-taping discussion of objectives 
with the objectives you might re-identify as part of the mini-lesson itself. As soon as the camera clicks on and the lesson begins, your fellow participants become students who are approaching your mini-lesson with fresh eyes. To be certain that you clearly separate your introduction for colleagues from the actual mini-lesson, pre-arrange a given signal with the cameraperson. A definite pause and a nod should indicate the beginning of the mini-lesson to both your audience and the cameraperson. After that, relax and enjoy your teaching.

Ideally, every mini-lesson will conclude in the allotted ten minutes. In actual practice, however, many instructors are still presenting material when the ten minutes elapse. Please do not be offended when the workshop facilitator signals both you and the cameraperson to stop. This practice may seem rude, particularly if you are in an unusually dynamic segment of the lesson, such as the conclusion. Frustrating as it may be, adhering to the ten-minute limit is the only way to ensure equal participation. Plus, running out of time is a realistic classroom concern. Unless you identified closure as one of the two teaching skills you were concentrating on, a ten-minute tape of an incomplete lesson will provide sufficient material for effective feedback.

The STUDENTS, including those who are offering mini-lessons, act as interested observers.

Perhaps one of the most consistent comments about the microteaching experience concerns the difficulty of playing the roles of both student and analyst. There is no easy solution to this duality other than a flexible willing suspension of disbelief coupled with as natural a classroom setting as possible. This means for example, that you may want to ask questions about material that you already know, but students may not. Please remember, however, that this is not a role-playing situation where you might, for instance, deliberately cause classroom disruptions to watch the instructor's response. Your questions, comments, and body language should help instructors anticipate what their students might actually experience during a similar lesson. At the same time you are reacting as a student, you must keep your critical faculties attuned to what is occurring in the simulated classroom. You'll want to make notes on the mini-lesson form the instructor distributed, remembering to comment specifically on those areas where feedback was requested.

The DISCUSSION LEADER channels discussion constructively as the student/analysts prepare for the feedback session. 
When guiding the discussion, be certain that the group focuses initially on the two specific skills the instructor wants feedback on. Keep the tone positive and constructive, perhaps asking questions such as, "How do we provide $\mathrm{X}$ with the most help?" "Do we really want to tell $\mathrm{X}$ that if she cannot do anything to change this behavior?" "How do we phrase these comments to get $\mathrm{X}$ to reflect on possible changes?" Try to draw out all the members of the group, including those who will also be offering mini-lessons.

Watch the time carefully so that the group can take the final few minutes to prepare the final feedback.

The RECORDER accurately paraphrases and summarizes the group's comments.

When preparing your summary, remember you are aiming for the gist of an idea, not exact phrasing. If the discussion is as animated as it should be, you won't have time in any case to copy verbatim comments during the ten-minute period. Because you are reflecting the opinions of a group, you will want to use phrasing such as "Most of us felt ..." or "A few people suffering from math anxiety indicated...." Just prior to your feedback session, work out with the group the best way to get the instructor thinking about possible areas of improvement. Decide, for example, when a question might be more helpful than a direct statement. Instead of "Some of us felt the material was too simple," try asking, "Did you deliberately simplify your presentation because you were targeting a basic psychology class?"

Organize the group's ideas under the two teaching skills/abilities you are providing feedback for, not in the order that the comments arose. You are providing a summary, not a transcript. Alternatively, each group might want to organize the feedback by giving one positive comment (something the person should continue doing) and one negative comment (something the person could improve or alter).

The SPOKESPERSON diplomatically presents the group's ideas to the instructor giving the mini-lesson.

When presenting your group's summary to the instructor, remember to be as positive as possible, perhaps beginning with the strong points about the mini-lesson. When noting negative points, use phrases such as "We wondered..." or "A couple of us became confused because...." Definitely include the other group members in your presentation, perhaps asking some of them to clarify points. As you talk with the instruc- 
tor, include your colleagues also through your glances at the group members to verify the accuracy of your summary. With a constructive, supportive tone, your presentation should result in a friendly exchange of ideas, stimulating instructors to continue doing positive things and to reflect on possible changes.

The CAMERAPERSON captures everything of importance during the mini-lesson, including pseudo students' responses. 